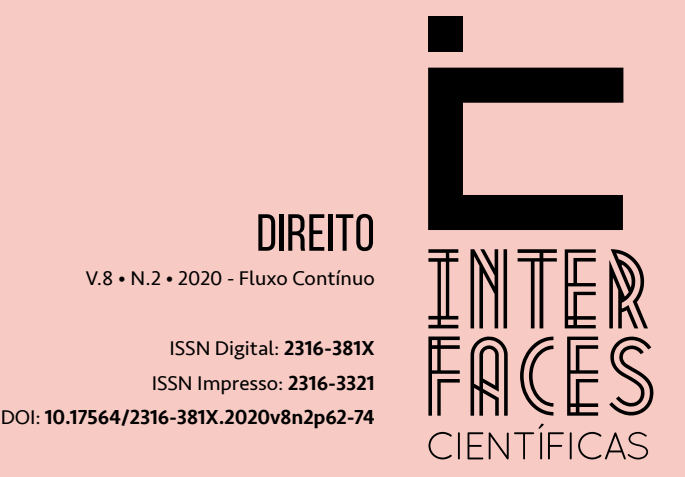

\section{O ARTIGO CIENTÍFICO COMO MERCADORIA ACADÊMICA}

SCIENTIFIC ARTICLE AS ACADEMIC GOODS

ARTÍCULO CIENTÍFICO COMO BIENES ACADÉMICOS

\section{RESUMO}

0 presente trabalho busca identificar o artigo científico como um dos meios mais privilegiados da construção e comunicação do conhecimento produzido na universidade e situar, no processo de produção e publicização do conhecimento, o papel do artigo científico como um dos meios mais privilegiados nos processos de avaliação do trabalho docente. Trata-se de um estudo teórico com base na análise do trabalho produtivo na perspectiva marxista e de análise documental, a partir de documentos oficiais do MEC e da CAPES que estruturaram as alterações nos processos avaliativos do trabalho docente, a partir de 1995. Ao apontar para esse construto, este estudo permite discutir as mudanças sócio-históricas no meio universitário, que transformam o artigo científico em mercadoria nos processos de avaliação acadêmicos.

\section{PALAVRAS-CHAVE}

Produtivismo Acadêmico. 


\section{ABSTRACT}

The present work seeks to identify the scientific article as one of the most privileged means of the construction and communication of knowledge produced in the university and to situate, in the process of production and publicization of knowledge, the role of the scientific article as one of the most privileged means in the evaluation processes. of teaching work. This is a theoretical study based on the analysis of productive work in the Marxist perspective and documentary analysis, based on official documents from Mec and Capes that structured the changes in the evaluation processes of teaching work, from 1995 on. For this construct, this study allows us to discuss the socio-historical changes in the university environment, which transform the scientific article into a commodity in the academic evaluation processes.

\section{KEYWORD}

\section{Academic Productivism}

\section{RESUMEN}

El presente trabajo busca identificar el artículo científico como uno de los medios más privilegiados de la construcción y comunicación del conocimiento producido en la universidad y situar, en el proceso de producción y divulgación del conocimiento, el papel del artículo científico como uno de los medios más privilegiados en los procesos de evaluación del trabajo docente. Este es un estudio teórico basado en el análisis del trabajo productivo en la perspectiva marxista y el análisis documental, basado en documentos oficiales de MEC and Capes que estructuraron los cambios en los procesos de evaluación del trabajo docente, desde 1995 en adelante. Para esta construcción, este estudio nos permite discutir los cambios sociohistóricos en el entorno universitario, que transforman el artículo científico en una mercancía en los procesos de evaluación académica.

\section{PALABRA CLAVE}

productivismo académico 


\section{INTRODUCÇÃO}

O presente estudo, realizado no Programa de Pós-Graduação em Educação, da Faculdade de Educação da Universidade Federal de Goiás (UFG), é resultado de uma trajetória profissional iniciada há três décadas no exercício profissional como livreira em Goiânia e, posteriormente, como professora na universidade, sempre atuando na área da promoção do livro, da leitura e da biblioteca.

De 2006 a 2013, com a experiência na direção do Centro Editorial e Gráfico (CEGRAF) a relação com o livro se ampliou, uma vez que passou a se pautar em toda a sua cadeia produtiva: o recebimento de originais, a avaliação pelo conselho editorial, a definição da linha editorial, a revisão para adequação de linguagem, a normalização, o registro do International Standard Book Number (ISBN), a definição de um projeto gráfico capaz de conferir identidade, a impressão e a divulgação. A experiência acumulada na direção da Editora UFG revelou, enfim, as entranhas do processo editorial acadêmico e as transformações pelas quais passava a divulgação do conhecimento científico.

As atividades de uma editora universitária traduziam as formas de divulgação do conhecimento produzido por uma universidade, a partir da política editorial adotada pela instituição. Uma editora universitária podia então desenvolver, por meio de sua política editorial, um projeto intelectual de preservação do pensamento humano. E essa política só se consolidaria ao se nortear por critérios comprometidos com o ensino, com a produção da ciência, da tecnologia, da arte e da cultura - enfim, os pressupostos básicos do tripé acadêmico "ensino, pesquisa e extensão".

À qualidade científica, artística e cultural deviam estar aliados outros compromissos determinados pela forma de produção dos livros, tais como o de satisfazer ao público-leitor, o de estabelecer linguagens, o de atender às demandas e, acima de tudo, o de assumir os espaços não ocupados pelas editoras comerciais.

No caso de uma instituição pública de ensino superior, o papel se ampliava quando se produziam livros que deviam também contribuir para a formação de leitores universitários em seus campos específicos. Nesse sentido, os conselhos editoriais se tornavam responsáveis pela formalização das políticas que norteariam suas publicações: o quê? Para quem? Por quê? Como? Onde? Quando? Em razão desses quesitos, a editora universitária, dotada de política editorial definida por um conselho de representantes, competente, respeitado e independente, não correria o risco de ser confundida com gráficas que alugam selos para serem colocados nas capas de livros.

No entanto, percebeu-se que os procedimentos em torno do livro eram de difícil entendimento e aceitação. Não atendiam à rapidez de produção e de circulação necessária aos interesses postos por políticas de avaliação institucionais. Daí, iam na contramão desses pressupostos ao buscar formatos e linguagens que se ajustassem à especificidade das áreas, de seus conteúdos e de suas linguagens próprias. Assim, a atuação da editora no meio acadêmico da UFG gerou novas demandas por publicação na carreira acadêmica e por avaliações institucionais para atender às exigências dos órgãos de fomento, o que passou a afetar a produção intelectual.

As exigências crescentes de publicação, a partir de uma política em andamento na universidade, tendiam a valorizar a produção acadêmica com base em critérios quantitativos, em especial no quesi- 
to "produção bibliográfica”, em veículos de divulgação qualificados. Nessa política, caracterizada por muitos como "produtivista", o artigo de periódico indexado ganhava protagonismo.

A demanda de fortalecimento dos periódicos científicos apontava para a prioridade da publicação do artigo científico como forma de divulgação do conhecimento acadêmico produzido. Assim, apesar de toda a experiência acumulada em torno da publicação de livro e da compreensão da importância desse processo para a universidade, o artigo científico tornou-se a forma mais privilegiada de alcançar o sucesso acadêmico. Vale dizer que, durante essa trajetória, ao compor a diretoria da Associação Brasileira de Editoras Universitárias (ABEU), no período de 2011 a 2012, verifica-se que o papel das editoras universitárias era constantemente questionado.

Essa questão se devia às transformações presentes no processo de publicização do conhecimento que vinha sendo instituído, em especial pelos processos de avaliação da produção acadêmica e à importância crescente do artigo científico no contexto editorial.

Essa constatação me levou ao questionamento desse modelo de divulgação do conhecimento acadêmico que ganhava tamanha força, principalmente quando um fato, que será visto a seguir, chamou a atenção.

\section{OS IMPRODUTIVOS DA USP}

Nos estudos realizados em torno do tema, um acontecimento tornou-se emblemático para situar a questão do produtivismo acadêmico. Em 1988, uma matéria da Folha de São Paulo relacionou nomes de professores e pesquisadores da Universidade de São Paulo (USP) que não teriam publicado nenhum trabalho científico no período de 1985 a 1986, com base em informações fornecidas pela Coordenadoria de Administração Geral da Reitoria daquela universidade. Esse episódio, conhecido como “a lista dos improdutivos da USP”, serviu simbolicamente de referência para as transformações que se intensificariam nas instituições de ensino superior brasileiro, a partir da década de 1990.

Com a divulgação da lista, chegou-se à constatação de que $25 \%$ dos professores em regime de dedicação exclusiva nada tinham apresentado ao público no período de 1985 a 1986. Para efeito desses cálculos foram considerados: artigos de periódico, artigos de jornais, resenhas, livros, tradução, materiais audiovisuais e trabalhos apresentados em eventos. Com base em uma análise meramente quantitativa, uma vez que não se levou em conta a relevância científica do material publicado, a USP apresentou o nome, o regime de trabalho, o tempo de serviço do docente, bem como o perfil de cada unidade acadêmica, elencando a quantidade de professores e o quantitativo total de publicações.

A reportagem da Folha de São Paulo defendia a necessidade do aperfeiçoamento dos métodos de avaliação da atividade acadêmica, sugerindo que o baixo nível de produção dos professores da USP exigia uma análise minuciosa, pública e intransigente. Segundo a matéria, a elaboração da referida lista constituía um importante passo nesse objetivo, pois era a primeira vez que uma universidade brasileira se propunha a expor não só esse tipo de avaliação, mas também aquilo que produzia.

2 Os improdutivos da USP. Folha de São Paulo, São Paulo, p. A-2; 28-31, 21/02/1988. Disponível em: http://acervo.folha.com. $\mathrm{br} /$ leitor.do?numero=10150\&anchor=4285568\& origem=busca\&pd=c600d39a852e $71 \mathrm{cfdabe} 19 \mathrm{e} 3 \mathrm{a} 5 \mathrm{e} 13603$. 
A matéria, justificando a iniciativa da USP, sustentava que a produção intelectual norteava a avaliação no mundo desenvolvido, uma vez que, nas atribuições fundamentais da sociedade moderna, cabia às universidades a responsabilidade pela organização e difusão do conhecimento. Essa tarefa pressupunha o ensino, a pesquisa e a extensão, como serviços prestados à comunidade. Só seriam pertinentes então os conhecimentos incorporados ao patrimônio intelectual da humanidade, por meio de sua divulgação.

O então reitor da USP, José Goldemberg, explicou que a elaboração da lista correspondia a uma avaliação necessária para que a universidade se justificasse perante a sociedade. Ela estaria, assim, prestando contas das verbas que consumia, bem como demonstrando estar cumprindo com suas finalidades sociais: formação de pessoal altamente qualificado e produção de conhecimento crítico inovador e relevante para o país. Goldemberg afirmou ainda que a avaliação era um importante instrumento para a alocação de recursos e sua otimização, uma vez que desenvolvia mecanismos capazes de estabelecer critérios de decisão.

Convém ressaltar que a divulgação dessa lista provocou um intenso debate público por meio de opiniões, análises e desagravos, com dezenas de artigos diários durante quase um mês ${ }^{3}$. As posições assumidas pelos autores, muitas delas contrárias à divulgação da lista, questionaram a administração da reitoria pelo uso dado a um mecanismo interno da USP, desconhecido até pelos professores. Apenas dois deles, Eunice Ribeiro Durham e Rogério César de Cerqueira Leite, manifestaram-se a favor da elaboração e da publicação da lista com os indicadores individuais de produção, alertando apenas que ela deveria ser mais bem executada.

3 Estas foram respostas de intelectuais, publicadas na Folha de São Paulo no período de 24/02 a 18/03/1988:

(24/2) “Avaliação institucional e execração individual”, por Eunice Ribeiro Durham;

(24/2) “Perfil do professor improdutivo", por Marilena Chaui;

(25/2) “Falsa transparência”, por Francisco Weffort;

(26/2) “Marajás e improdutivos", por Walter Colli;

(29/2) “A transparência recoberta pela leviandade”, por Maria Tereza Leme Fleury;

(29/2) “Erramos”, por Rui de Brito Álvares Affonso;

(29/2) "O efeito devastador da lista dos improdutivos", por Modesto Carvalhosa;

(1/3) "O estranho caso do funcionário X e o professor Y", por Nicolau Sevcenko;

(1/3) “A USP, a Folha e a nova sociedade civil”, por Carlos Guilherme Mota;

(1/3) "Jornal e universidade", por Antônio Candido;

(3/3) “Comoção e avaliação na USP”, por Rogério Cezar de Cerqueira Leite;

(8/3) “Avaliando a avaliação", por Newton Lima Neto;

(6/3) "O imperador contra-ataca”, por José Arthur Giannotti;

(10/3) “USP e ciência no Brasil”, por Maria Isaura Pereira de Queiroz;

(11/3) “Depois da tempestade”, por Simon Schwartzman;

$(11 / 3)$ "Lacunas de um debate”, por Boris Schnaiderman;

(17/3) "Essência e aparência”, por Florestan Fernandes;

(15/3) “USP x Folha - para além da indignação”, por Paul Singer;

(16/3) "Invectiva contra bárbaros 2", por Maria Sylvia de Carvalho Franco;

(18/3) “O valor da nova inquisição”, por Nestor Goulart Reis;

(18/3) “A intelligentsia e os outros”, por Carlos Alberto Idoeta. 
Entre os artigos que criticaram a publicação da lista de improdutivos, destacam-se o de Marilena Chauí, que apresentou o perfil do professor improdutivo a partir de sua trajetória; o de Francisco Weffort, que tratou da falsa transparência contida na divulgação da lista; o de Maria Tereza Leme Fleury, que apontou a leviandade dessa transparência; e o de Nestor Goulart, que defendeu a ideia de inquisição presente na lista dos improdutivos. Ademais, a Folha de São Paulo contava com a contribuição intelectual, constante ou eventual, de muitos professores tidos como improdutivos, como Antônio Cândido, José Arthur Giannotti, Paul Singer, entre outros.

Esse fato tornou-se um importante marco sobre as concepções e práticas universitárias de avaliação, dando destaque à ascensão de um processo caracterizado como produtivismo, que viria a ser assimilado de modo natural nos meios acadêmicos. Com efeito, as práticas gestadas e iniciadas nesse período consolidaram um modelo de avaliação com novos marcos conceituais, políticos e ideológicos, cujas premissas se ancoravam na administração e no controle da produção acadêmica.

Marcado por uma concepção produtivista, esse modelo, que viria influenciar a construção de um sistema nacional de avaliação implantado no Brasil, no tocante ao trabalho acadêmico, se apoiou nas exigências de publicação. Daí, o artigo científico se tornaria um dos dispositivos mais importantes na avaliação do desempenho do docente.

A divulgação da lista de improdutivos apontaria para mudanças nas concepções e práticas universitárias de avaliação e revelaria dispositivos que se tornariam, sutilmente, mais presentes nas técnicas de medida da produção intelectual. Esses aspectos do nascente produtivismo, com o passar dos anos, se tornariam procedentes no meio acadêmico (SCHMIDT, 2011).

\section{PRODUTIVISMO NO MEIO ACADÊMICO}

O modelo produtivista se constitui, no contexto da modernização da universidade, sob a égide da produtividade acadêmica que estabelece critérios de produção e rendimento pela lógica da organização empresarial do trabalho imposta pela globalização. Ainda segundo Schmidt (2011), o produtivismo inscreve-se no processo de modernização da universidade como ideias e práticas voltadas para a adaptação de sua produção científica e tecnológica, bem como para a competividade nos âmbitos nacional e internacional.

0 tema do produtivismo tem sido estudado por diferentes autores (SGUISSARD; SILVA JR, 2009; LUZ, 2005; ALCADIPANI, 2011; WATERS, 2006; BIANCHETTI; MACHADO, 2009; SILVA JR., 2017) que delineiam uma apreensão quantitativa da ciência, induzida pelos sistemas de avaliação da produção acadêmica. O ideário produtivista torna-se indissociável da racionalidade mercantil, pois ambos estão envolvidos com o processo de transformação do trabalho acadêmico e de seus atores.

0 produtivismo impõe um modelo instrumentalizado de apreciação e produção do conhecimento e reduz essa apreciação à medida e a atividade acadêmica aos seus produtos. Segundo Luz (2005, p. 43), por produtivismo acadêmico entende-se "o quantum de produção intelectual, sobretudo bibliográfica, desenvolvida em um tempo específico, crescente [...] necessário para conservar os pesquisadores na sua posição estatutária em seu campo científico". 
Todo esse processo, que já completa trinta anos desde o caso da USP, ocorre em um contexto de crescente globalização da economia e de neoliberalização da política e seus desdobramentos no campo ideológico, que atinge todas as esferas da vida social e cultural, chegando até as determinações mais subjetivas.

Nessa perspectiva, é de fundamental importância compreender como as políticas de avaliação tornam-se um instrumento do produtivismo que legitimam a lógica de uma ordem formal à qual a produção acadêmica deve se submeter. E, com o estabelecimento de uma hierarquia de áreas do conhecimento, das instituições, dos programas de pós-graduação - a partir de critérios que combinam adaptação e controle -, necessariamente, induzem os professores e pesquisadores a se adequarem em busca de uma avaliação favorável.

Com base nessas premissas, o tema deste trabalho pode então ser estruturado. Ao identificar o artigo científico como um dos meios mais privilegiados da construção e comunicação do conhecimento produzido na universidade, o presente trabalho tem como objetivo compreender como a atividade científica passa a ser direcionada com base em classificações que se focam em resultados e produtos, influenciados por um modelo produtivista.

A partir dessa proposição, este trabalho busca situar, no processo de produção e publicização do conhecimento, o papel do artigo científico como um dos meios mais privilegiados nos processos de avaliação do trabalho docente. Nele se discute também quais são as determinações constitutivas da centralidade do artigo científico, como produto mais valorado, na universidade pública brasileira e como ele se torna uma mercadoria acadêmica, que afeta sobremaneira as condições do trabalho e da carreira docentes.

Trata-se, portanto, de um estudo teórico com base na análise do trabalho produtivo na perspectiva marxista e da parte documental, a partir de documentos oficiais do Ministério da Educação (MEC) e da Coordenação de Aperfeiçoamento de Pessoal de Nível Superior (CAPES) que estruturaram as alterações nos processos avaliativos do trabalho docente, a partir de 1995. Ao apontar para um construto, este estudo permite discutir as mudanças sócio-históricas no meio universitário, que transformam o artigo científico em mercadoria nos processos de avaliação acadêmicos.

\section{NEOLIBERALISMO, A REFORMA DO ESTADO E O TRABALHO ACADÊMICO}

O Neoliberalismo e reforma do Estado, no contexto da globalização, determina mudanças econômicas a partir da década de 1990. Essas mudanças impõem uma lógica produtivista como forma de regulação na reorganização mundial da economia e do trabalho. Com isso, a produtividade no processo de trabalho assume o ponto central dessa forma de acumulação do capital, que altera as condições gerais de produção e do mundo do trabalho.

A neoliberalização na universidade pública operou significativas alterações no trabalho docente, materializando um determinado tipo de trabalho produtivo: a publicação científica no formato de artigo de periódicos. 0 artigo científico se materializa a partir de um processo de homogeneização de formas e valores e se fortalece como ícone na metrificação da avaliação da produtividade. 
Questionam-se assim as concepções de avaliação que orientam as intervenções políticas contemporâneas, a atuação da Capes na implantação de uma política de avaliação como instrumento de controle da produção acadêmica e científica, com o artigo científico se configurando como uma forma de mercadoria nesse processo.

Com base nesses temas e na bibliografia disponível, este trabalho teve como proposito o desvelamento dos mecanismos que alçaram o artigo de periódico a um patamar de relevância mercadológica no meio acadêmico.

Ao eleger o protagonismo do artigo científico no processo de avaliação do trabalho docente, está posta a necessidade de compreensão de como esse processo se configura no meio acadêmico. As transformações nas políticas internas e externas de avaliação da produção intelectual de professores e pesquisadores apontam para um modelo orientado por demandas de produtos e serviços, que, por sua vez, definem formatos, ritmos, prazos e financiamento.

Ao identificar a característica valorativa dos artigos científicos publicados em revistas com alto fator de impacto, a produção do conhecimento científico passa a basear-se na citação como fonte de reconhecimento da publicação, ou seja, como indicador capaz de avaliar a influência de um artigo.

Nessa perspectiva, algumas questões surgiram: como o trabalho docente passa, na década de 1990, por profundas alterações na estrutura, na organização e na gestão da universidade, a partir da uma reforma do aparelho do Estado, que tem como modelo econômico os pressupostos neoliberais? Como o processo de produção do conhecimento afeta e reorienta o trabalho docente e a produção intelectual em universidades públicas brasileiras? $\mathrm{E}$, consequentemente, como o artigo científico se constitui em um produto altamente valorizado no processo de avaliação institucional e docente e se materializa como mercadoria?

Para compreender a racionalidade das reformas impostas pelo modelo neoliberal no contexto da globalização - bem como para situar a introdução da lógica da produtividade como forma de regular a reorganização mundial da economia e do trabalho -, torna-se necessário retomar a história recente do país.

A noção da produtividade se instaura a partir do estabelecimento de modelos de avaliação, como uma necessidade essencial para o funcionamento da produção científica, para o delineamento de resultados pregressos dos pesquisadores, departamentos e instituições. 0 desempenho acadêmico é medido em números, como foco de análise; a necessidade de publicação é tratada como uma mercadoria, que passa a orientar a vida acadêmica, do ponto de vista individual e institucional.

Na perspectiva de Silva Jr. (2017, p. 87), professores e pesquisadores estão “sendo organizados como mercado produtor e consumidor de artigos", e "visam menos a socialização de conhecimento e se caracterizam mais como marketing do produto e do próprio pesquisador". Assim, a universidade, lócus privilegiado da produção do conhecimento, é instada a fazer parte da economia de mercado, razão pela qual os conceitos de produtividade ou improdutividade são definidos quase que exclusivamente pelo aspecto quantitativo.

0 trabalho na universidade se redimensiona a partir da publicação de artigos em periódicos de ampla circulação, o que tem alicerçado a base para a construção de uma produção consolidada e legitimada acerca dos objetos de investigação. Para Silva Jr. (2017, p. 88), não é a pauta de uma pesquisa 
que determina a produção do pesquisador/professor, mas sim uma demanda posta pelo mercado e regulada por políticas institucionais, impondo que o trabalho acadêmico seja publicado em periódicos qualificados e em quantidade significativa.

0 trabalho acadêmico se reconfigura, então, no entendimento do que o ensino e a pesquisa passam a ter sob o padrão organizacional: adaptar a universidade, a partir de uma proposta de modernização, à lógica capitalista, tomando-a como uma organização prestadora de serviços, regida pelas ideias de qualidade, de avaliação e de flexibilização.

A autonomia significa, para Chauí (1999, p. 2), o "gerenciamento empresarial da instituição". E a autora continua: "flexibilização é o corolário da autonomia". Assim, flexibilizar quer dizer: (i) a eliminação do regime único de trabalho dos professores, precarizando a docência; (ii) a simplificação da gestão financeira e da prestação de contas; (iii) a reformulação dos currículos de graduação e pós-graduação às demandas do mercado de trabalho; (iv) a decisão de separar docência e pesquisa.

A noção de qualidade é definida como competência e excelência, com base em processos avaliativos estabelecidos por critérios de atendimento às demandas de modernização econômico-social. Essa relação é medida, pela produtividade, que, por sua vez, é orientada pelos critérios de quantidade, tempo e custo. No entanto, os critérios de produtividade não questionam o que é produzido, como, para que, ou o que se produz, operando uma inversão da qualidade em quantidade. Seguindo a tendência predominante no mundo do trabalho, sob a acumulação flexível, o trabalho docente é flexibilizado, intensificado e precarizado para atender ao produtivismo.

Este se caracteriza pelo crescimento contínuo de produtos, em especial pelas formas de produzir e publicar um número crescente de artigos em revistas conceituadas do seu específico campo de atuação. Intensifica-se então a tendência geral, dessa fase do capitalismo, de transformar todos os tipos de bens em mercadorias.

A mercantilização do regime de trabalho dos professores e pesquisadores afeta decisivamente as duas principais funções da universidade: a pesquisa científica e a educação de nível superior. As universidades reconfiguram o trabalho acadêmico para um processo de produção de conhecimento mercadoria, dando centralidade ao artigo científico. A compreensão desse processo requer a discussão da noção de trabalho em Marx.

0 trabalho, entendendo como a única mercadoria que produz mais-valor, se constitui um dos meios de valorização do capital, uma vez que, segundo Marx, a relação entre trabalhador e capitalista é desigual, mesmo que aparentemente possua mercadorias em iguais condições. 0 produto específico do modo de produção capitalista é a mais-valia gerada pelo trabalho produtivo, ou seja, o trabalho excedente não recebido pelo operário.

O capital (ou dinheiro) com que o capitalista compra a força de trabalho é constituído por trabalho morto e acumulado como capital. 0 capital constituído de trabalho morto se apropria da força física do trabalhador para se reproduzir por meio da mais-valia incorporada na produção de mercadorias.

A partir dessas considerações, este trabalho discute a natureza do trabalho do professor nas instituições públicas de ensino superior, a partir de sua reconfiguração em que ensino e a pesquisa passam a ter sob o padrão organizacional, tomando-os como uma organização prestadora de serviços, regida pela lógica do produtivismo acadêmico. 
Com base nessa premissa, as pesquisas em torno das reformas ocorridas na universidade pública brasileira ao longo dos últimos vinte anos, abordam as causas da profunda transformação no fazer acadêmico. Para Silva Jr. e Pimenta (2016), a racionalidade do modo de reprodução do capital, sob a predominância financeira, explicita a transformação gradual da universidade pública brasileira em uma das partes da produção da indústria de serviços. Com um tipo de produção científica, há predominância da epistemologia das áreas do conhecimento que têm maior potência para agregar valor ao capital. É nelas em que mais se estabelecem novas relações de trabalho entre capital-trabalho e mais-valia.

A universidade tem se tornado parte da produção da indústria de serviços. Somada ao processo de valorização aumenta-se a produtividade no trabalho e colocam, na perspectiva de Antunes (2013), o trabalho produtivo em lugares nunca imaginados. No caso do trabalho do professor na pós-graduação, transforma-se o conhecimento em um valor que pode ser agregado a uma mercadoria no processo de produção.

O trabalho imaterial, mesmo que não seja dominante, passa a ser parte da cadeia de valor. Silva Jr. e Pimenta (2016, p. 176) apontam para a complexa divisão social do trabalho, dos tempos contemporâneos e da nova relação do trabalho imaterial produtivo na área de serviços, das pesquisas e do desenvolvimento tecnológico, "mostrando o quanto o trabalho do professor da pós-graduação é predominantemente produtivo".

A universidade passa a intensificar seu compromisso com o crescimento econômico, ao ser operada pela ótica mercantil e com a reconfiguração de sua identidade institucional gestada na pós-graduação, determinada pela Capes e pelo Conselho Nacional de Desenvolvimento Científico e Tecnológico - CNPq e suas ações de indução, regulação e controle. A pós-graduação se assume como referência da efetiva reforma universitária, com base em um modelo de avaliação e indução da pesquisa, estabelecido pela naturalização do produtivismo acadêmico, bem como pela valorização da quantidade de produtos em detrimento da qualidade do processo de pesquisa. Para Sguissardi e Silva Jr. (2009, p. 62), tal processo

[...] consiste em afirmar que o núcleo da ideologia do produtivismo acadêmico, como a política de Estado e de cultura institucional, tem como sua mais completa tradução, no âmbito filosófico, o pragmatismo, e no âmbito econômico, a mercadorização da ciência e da inovação tecnológica [...].

A noção de produtivismo acadêmico está voltada para uma produção massificada, fundamentada em um padrão produtivo organizacional e de visível avanço tecnológico a partir da introdução de técnicas de gestão da força de trabalho próprias da fase informacional. A discussão do produtivismo na produção intelectual - que não é um processo apenas brasileiro, mas de âmbito internacional requer a compreensão da natureza efetiva do trabalho intelectual e a relação dos meios de produção no interior do processo do trabalho acadêmico.

Assim sendo, ao longo dos últimos vinte anos, as mudanças institucionais promovem gradativas alterações na natureza do trabalho acadêmico, em conformidade com um modelo de neoliberalização globalizada, que exalta a lógica produtivista por meio de um processo de mercantilização dos produtos acadêmicos. 
A trajetória consistente de incremento da produção científica, que promove o respeito da comunidade acadêmica, só se consolida pela avaliação. Nesse sentido, dois movimentos opostos e inconciliáveis se apresentam na produção do conhecimento: (i) a natureza social, útil e transformadora do conhecimento produzido e sua natural necessidade de divulgação; (ii) a imposição da busca do reconhecimento social, por parte da comunidade científica e das agências de fomento, conduzindo a práticas que se reduzem a um modelo hegemônico.

0 artigo científico, cujo objetivo natural é o de veicular as pesquisas, passa a ser superado pelas induções de publicação desenfreada e de forma fracionada, para atender às demandas, políticas e gestões, além de regular a produção acadêmica. A produção e o consumo dos artigos científicos - tal qual ocorre com qualquer mercadoria no capitalismo globalizado - apresentam fluxos que movimentam bens, serviços e conhecimento. Naturalizam-se, no cotidiano acadêmico, práticas do ideário neoliberal, por meio de uma produção contínua, que precisam ser renovadas indefinidamente.

A lógica produtivista promove a intensificação do trabalho docente e uma pressão para que 0 pesquisador se equipare a um empreendedor do setor privado. Para isso, ele tem de disputar espaço nas publicações, nos editais, com o propósito de obter reconhecimento da comunidade científica e de fazer propaganda de si mesmo.

Ao tornar-se mercadoria, o artigo científico parece ser dotado de uma autonomia que controla seus autores e os impele a trabalhar na direção exigida por demandas externas ao processo de produção do conhecimento. No entanto, não há lugar para todos na luta por publicação nos espaços editoriais mais reconhecidos, nos quais só alguns pesquisadores alcançam o topo da pirâmide.

A Capes, apesar de não definir explicitamente a noção de qualidade, promove práticas editoriais condicionadas por indicadores avaliados pelo Qualis. É possível extrair do modelo que um periódico científico de qualidade é aquele que possui: reconhecimento em sua área de atuação, ampla circulação, indexação em bases de dados reconhecidas nacional e internacionalmente, demanda de publicação de artigos provenientes das mais diferentes instituições.

Assim, esses fatores orientam a definição de qualidade na produção científica brasileira, medida pelos indicadores do Qualis, que se propõe a promover o reconhecimento científico dos periódicos, embora, no processo de avaliação, apenas $25 \%$ dos títulos possam alcançar a avaliação máxima, A1.

Para finalizar, fica claro que professores e pesquisadores estão diante de um processo de incorporação de pressupostos de uma organização social que regulamenta a atividade científica, em um formato mais valorizado. Isto se dá em razão da estrutura presente no artigo científico, que padroniza, metrifica e garante a reprodução de uma forma de conhecimento, com base em um sistema de controle e regulação reconhecidos pelo atual Sistema de Ensino Superior brasileiro. 


\section{REFERÊNCIAS}

ALCADIPANI, Rafael. Resistir ao produtivismo: uma ode à perturbação acadêmica. Cad. EBAPE.BR, Rio de Janeiro, v. 9, n. 4, dez. 2011.

ANTUNES, Ricardo. A degradação do trabalho no Brasil - entrevista [maio 2013]. Entrevistadora: Cirley Ribeiro. São Paulo: TV Boitempo, 2013. (6 min 30s). Entrevista concedida a Rádio Cultura. Disponível em: https://www.youtube.com/watch?v=gcJ3kBzfRFs. Acesso em: 1 jun. 2018.

BIANCHETTI, Lucídio; MACHADO, Ana Maria Netto. Trabalho docente no stricto sensu: publicar ou morrer. In: FIDALGO, F.; OLIVEIRA, M. A. M.; FIDALGO, N. L. R. A intensificação do trabalho docente: tecnologias e produtividade. Campinas, SP: Papirus, 2009. p. 49-89.

CHAUÍ, Marilena. A universidade operacional. Folha de São Paulo, São Paulo, 9 maio 1999. Caderno Mais.

LUZ, Mandel. Prometeu acorrentado: análise sociológica da categoria produtividade e as condições atuais da vida acadêmica. Physis: Rev. Saúde Coletiva, Rio de Janeiro, v. 15, n. 1, p. 39-57, 2005.

SCHMIDT, Maria Luisa Sandoval. Avaliação acadêmica, ideologia e poder. Psicologia USP, São Paulo, v. 22, n. 2, p. 315-334, 2011.

SGUISSARDI, Valdemar; SILVA JÚNIOR, João dos Reis. Trabalho intensificado nas federais: pósgraduação e produtivismo acadêmico. São Paulo: Xamã, 2009.

SILVA JÚNIOR, João dos Reis. The new brazilian university: a busca por resultados comercializáveis: para quem? Bauru: Canal 6, 2017.

SILVA JÚNIOR, João dos Reis; PIMENTA, Alan Vitor. Predominância financeira, universidade de classe mundial e trabalho produtivo. In: FERREIRA, Suely; OLIVEIRA, João Ferreira (Org.).

Universidades públicas: mudanças, tensões e perspectivas. São Paulo: Mercado de Letras, 2016. p.159-177.

WATERS, Lindsay. Inimigos da esperança: publicar, perecer e o eclipse da erudição. São Paulo: Unesp, 2006. 


\section{(). (1) (-)}

Este artigo é licenciado na modalidade acesso abertosob a Atribuição-Compartilhalgual CC BY-SA

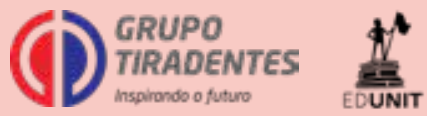

